Rev. Estud. Ling., Belo Horizonte, v. 27, n. 1, p. 49-72, 2019

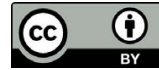

\title{
La variación en la representación del complemento verbal y la enseñanza de PB a hispanohablantes: un análisis de materiales didácticos de PLE
}

\section{The Variation in the Representation of the Verbal Complement and the Teaching of BP to Spanish Speakers: An Analysis of Didactic Materials of PFL}

\author{
Thaís Leal Rodrigues \\ Universidade Federal Fluminense, Niterói, Rio de Janeiro / Brasil \\ leal.thais@hotmail.com
}

Resumen: Este artículo tiene como tema la enseñanza de la representación del complemento verbal - objeto directo e indirecto - a hablantes de español. Se trata de hecho lingüístico variable en la lengua portuguesa de Brasil (PB), pues la enunciación del complemento verbal dentro de un texto o diálogo, en lengua portuguesa de Brasil, presenta varias posibilidades para su representación además del uso de los clíticos, prescripto por la gramática normativa. Se constituye, por lo tanto, un fenómeno en variación. Se pretende, en esta investigación, describir esa variable y evaluar sus implicaciones en el proceso de enseñanza y aprendizaje de PLE, así como examinar como este aspecto del PB ha sido tratado en los materiales didácticos dirigidos a la enseñanza de PLE. En otras palabras, se tiene el intuito de verificar como son presentados y enseñados los complementos verbales, en esos materiales, y averiguar si la variación lingüística está contemplada en el tratamiento de este tema. Se trata de una investigación que se basa en la teoría sociolingüística para analizar materiales didácticos, pues creemos que se debe presentar la lengua extranjera al alumno, de tal manera que se dé cuenta de toda su riqueza y variación, a fin de hacerlo capaz de interactuar en las diversas situaciones lingüísticas de habla y escritura.

Palabras clave: Sociolingüística; enseñanza de portugués como lengua extranjera; hispanohablantes. 


\begin{abstract}
The key theme of this article is the teaching of the representation of the verbal complement, both direct and indirect objects. That is a linguistic variable fact in Brazilian Portuguese (BP). The enunciation of the verbal complement in a text or dialogue in Brazilian Portuguese presents several possibilities for its representation besides the use of clitics prescribed by the normative grammar. Therefore, it constitutes a phenomenon in variation. This research aims to describe this variable and assess its implications for the Portuguese as Foreign Language (PFL) teaching and learning process, as well as examine how this aspect of BP has been treated in the educational materials aimed at teaching PFL. In other words, the intent of this investigation is to verify how verbal complements are presented and taught in these materials and determine if linguistic variation is considered in the treatment of this subject. This research is anchored on sociolinguistic theory in order to analyse teaching materials because it is my view that a foreign language should be presented to students in such a way that they can see all its richness and variation and, therefore, help them to be able to interact in different linguistic situations through speech and writing.
\end{abstract}

Keywords: sociolinguistics; teaching Portuguese as a foreign language; Spanishspeaking.

Recebido em 13 de novembro de 2017

Aceito em 20 de março de 2018

\title{
1 Introducción
}

El portugués y el español tienen el mismo origen latino, así que son lenguas muy próximas. Por eso es evidente que al aprender la lengua española un lusohablante presentará interferencias de su lengua materna en la fase inicial del aprendizaje y, de la misma manera, un hispanohablante será muy influenciado por el español, cuando aprenda el portugués, como afirma Santos:

Se por um lado essa semelhança facilita o entendimento do português logo aos primeiros contatos, por outro impede, na maioria das vezes, que o falante de espanhol se comunique na língua alvo, o português, sem as constantes interferências da sua língua nativa. (SANTOS, 1999, p. 49) 
Para Maia González (2008), la proximidad entre las dos lenguas no es tan grande como se imagina, especialmente cuando se trata de la variedad brasileña del portugués:

Se ha estudiado centenares de veces sobre la proximidad entre las lenguas española y portuguesa, pero esa cercanía parece ser, al menos en algunos aspectos, por lo menos moderada, sobre todo cuando se compara la variedad más estándar del español con el portugués de Brasil, incluso en el nivel de las variedades más informales de ambas lenguas. (MAIA GONZÁLEZ, 2008, p.1)

Este artículo presenta los resultados de la investigación realizada sobre la enseñanza de la representación del complemento verbal a hablantes de español, ya sea el objeto directo, o el objeto indirecto, hecho lingüístico variable en la lengua portuguesa de Brasil (PB). El trabajo consiste en un análisis de materiales didácticos de enseñanza de portugués a extranjeros (PLE), con el fin de verificar como son presentados y enseñados los complementos verbales, en los referidos materiales, y averiguar si la variación lingüística está contemplada en el tratamiento de este tema.

Varias investigaciones constataron que a partir del siglo XIX el PB empezó a presentar la pérdida del clítico acusativo de tercera persona del discurso. Paralelamente, los pronombres átonos comenzaron a ser reemplazados por los pronombres tónicos. Además, varios estudios (DUARTE, 2000; BERLINK, 1997; CYRINO,1997; TARALLO, 1983) demuestran el alto porcentaje de omisión de los objetos anafóricos. Tal hecho no ocurre en la lengua española, que, incluso en su expresión oral, presenta todos los objetos complementados por los pronombres átonos (MAIA GONZÁLEZ, 1999), lo que hace bastante limitada la posibilidad de ocurrir un OD anafórico sin representación por el pronombre.

Según Maia González (2008, p. 1, 1999, p. 166), portugués y español presentan diferencias en el ámbito de la realización de los sujetos y de los objetos pronominales, constituyendo lo que se denomina "inversa asimetría", esto es, una oposición que atañe a la presencia o ausencia de los pronombres personales sujeto y complemento en ambas lenguas. El ejemplo $1(\mathrm{a}, \mathrm{b})$ contiene la misma frase redactada en portugués y en español, para facilitar la comprensión de las diferencias comentadas. 
1(a) Eu comprei um presente para você. Vou te/lhe entregar $\underline{\emptyset}$ no dia do seu aniversário.

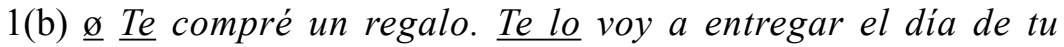
cumpleaños.

El ejemplo indica que mientras el PB manifiesta una tendencia a la realización del sujeto por medio del pronombre, el español, al contrario, presenta una necesidad de enfatizar el objeto, retomándolo por medio de clíticos y, muchas veces, duplicándolo. Por otro lado, el PB se caracteriza por una tendencia a la omisión del OD, al paso que, en español, es común omitir el sujeto (sujeto nulo). Para Maia González (2008, p. 2), dicho fenómeno constituye "uno de los aspectos más problemáticos en el proceso de aprendizaje de cada una de ellas por parte de los hablantes de la otra."

Nos parece, entonces, importante investigar la realización de los objetos - directo e indirecto - hecho lingüístico que puede hacer confuso el aprendizaje del portugués por parte de hispanohablantes, si no es enseñado del modo adecuado. Concordamos con Santos (1999, p. 53) cuando afirma que: "o ensino de português para falantes de espanhol deve ser diferente daquele voltado para falantes de outros idiomas". Eso se debe al hecho de que la enseñanza de portugués a hispanohablantes posee algunas especificidades, como la gran facilidad en la comprensión de la lengua extranjera, desde las primeras clases, y el proceso de aprendizaje más rápido, lo que puede causar una fosilización precoz de la interlengua. Por ello, hay una necesidad de desarrollar en los alumnos una consciencia metalingüística acerca las diferencias existentes entre las dos lenguas.

\section{La muestra analizada}

Se analizaron diez libros de enseñanza de PLE. Para la selección de los materiales, buscamos elegir libros de tipos variados, con público meta diversificado, a fin de investigar posibles diferencias entre ellos, en lo que concierne al tratamiento lingüístico-gramatical. Optamos por libros actuales (publicados o con edición desde los 2000), para verificar si hubo alguna evolución en la producción de esos materiales, por influencia de los recientes estudios de la Lingüística en el área específica de PLE, en comparación con investigación anterior (RODRIGUES, 
2012). Los materiales elegidos están relacionados a continuación, en orden alfabético.

1) Aprendendo Português do Brasil: um curso para estrangeiros. 4. ed. / Maria Nazaré de Carvalho Laroca; Nadime Bara; Sonia Maria da Cunha Pereira. Campinas: Pontes, 2003. (APB)

2) Bem-vindo! A língua portuguesa no mundo da comunicação. 8. ed. / Susanna Florissi; Maria Harumi Otuki de Ponce; Silvia R. B. Andrade Burim. São Paulo: Special Book Services Livraria, 2014. (BV)

3) Estação Brasil: português para estrangeiros. / Ana Cecília Bizon; Elizabeth Fontão. Campinas: Átomo, 2005. (EB)

4) Muito prazer: fale o português do Brasil. v. 2 intermediário. I Gláucia Roberta Rocha Fernandes; Telma de Lurdes Ferreira; Vera Lúcia Ramos. São Paulo: Disal, 2014. (MB)

5) Novo Avenida Brasil: curso básico de Português para estrangeiros 1. / Emma Eberlein O. F. Lima et al. São Paulo: Editora Pedagógica e Universitária, 2009. (NAB)

6) Panorama Brasil: ensino de português no mundo dos negócios. / Susanna Florissi; Maria Harumi Otuki de Ponce; Silvia R. B. Andrade Burim. São Paulo: Galpão, 2006. (PB)

7) Passagens: Português do Brasil para estrangeiros. / Rosine Celli. Campinas: Pontes, 2002. (PAS)

8) Português Via Brasil: um curso avançado para estrangeiros. I Emma Eberlein O. F. Lima; Samira A. Iunes. São Paulo: Editora Pedagógica e Universitária, 2005. (PVB)

9) Sempre amigos: fala Brasil para jovens. /Elizabeth Fontão; Pierre Coudry. Campinas: Pontes, 2000. (SA)

10) Tudo bem? Português para a nova geração. v. 1. 5. ed. / Susanna Florissi; Maria Harumi Otuki de Ponce; Silvia R. B. Andrade Burim. São Paulo: Special Book Services Livraria, 2012. (TB) 


\section{Fundamentación Teórica}

Esta investigación se fundamenta en los presupuestos de la Sociolingüística, corriente lingüística que se inició en los Estados Unidos, en la década de 1960, como reacción al generativismo chomskyano y al estructuralismo saussureano. Esa teoría concibe la lengua como un hecho social y está relacionada a otros campos del conocimiento, como la antropología, la sociología y la geografía lingüística.

Es en el libro Modelos sociolingüísticos que Labov (1983) presenta los principales conceptos de la nueva escuela, así como la metodología de su propuesta. Según la teoría laboviana, el componente social es fundamental en el análisis lingüístico, pues, como ya dijimos, en la Sociolingüística, la lengua está vista como fenómeno social. Otro aspecto importante de ese abordaje es que, para Labov, la lengua es un sistema heterogéneo. La heterogeneidad lingüística, pero no implica de ninguna manera un caos lingüístico, puesto que hay normas subyacentes a toda variación, así que puede ser sistematizada. La variación es inherente a las lenguas, sin embargo no compromete el buen funcionamiento del sistema lingüístico ni la comunicación entre sus hablantes

En fin, para la Sociolingüística, jamás se puede considerar como irrelevante un fenómeno en variación. Además, un sociolingüista no puede tener una posición prejuiciosa respecto a alguna variedad. Lo que muchos consideran un "error", para el sociolingüista es una variante, esto es, una posibilidad en la lengua. Por lo tanto, queda claro la importancia de la Sociolingüística en la formación docente.

En Brasil, la vasta producción sociolingüística ha aportado importantes parámetros pedagógicos para la enseñanza de portugués como lengua materna, teniendo en cuenta el abismo existente entre el portugués estándar y el portugués hablado por los estudiantes, mayormente los de escuelas públicas. La contribución de los estudios sociolingüísticos para la educación brasileña se debe, sobre todo, a la investigación sociolingüista de Bortoni-Ricardo (1984 y 1993), que señaló la necesidad de que la escuela promueva la enseñanza bidialectal que busque facilitar el aprendizaje de los alumnos hablantes de dialectos no estándar.

En la perspectiva de la Sociolingüística Educacional, el educador no puede tener una postura de falta de respeto en relación a los saberes del alumno y su manera de hablar. Ya no se puede pensar que es deber del profesor cohibir los usos de la lengua que se desvíen de la norma estándar, humillando a los alumnos. Como afirma Bortoni-Ricardo (2004, 
p. 38): "uma pedagogia que é culturalmente sensível aos saberes dos educandos está atenta às diferenças entre a cultura que eles representam e a da escola, e mostra ao professor como encontrar formas efetivas de conscientizar os educandos sobre essas diferenças".

Uno de los presupuestos de la Sociolingüística Educacional es el reconocimiento de que la competencia lingüística de los individuos demanda que ellos dominen los diferentes modos de expresarse en su propia lengua. Es obvio que el aporte de los resultados de la investigación sociolingüística variacionista para el área de enseñanza y aprendizaje no se limita a la lengua materna. También podemos identificar su frontera con la adquisición de lengua extranjera y, específicamente, de PB, teniendo en cuenta que los análisis de las variedades de las diferentes comunidades de habla proporcionan una descripción mucho más realista acerca del funcionamiento de las lenguas, sus gramáticas tradicionales y también de la importancia de los aspectos sociales y culturales en el aprendizaje de una lengua extranjera.

Una enseñanza de portugués de Brasil para extranjeros (PBE) que se base en la teoría variacionista posibilitará que los aprendices interpreten el significado de los usos variables de las formas lingüísticas identificadas en contextos marcados por la diversidad cultural. Esa clase de orientación pedagógica también hace que el alumno perciba la forma por la cual los hablantes nativos utilizan la variación para expresar sus identidades, especialmente cuando el aprendizaje se da en el contexto del país de la lengua aprendida.

Sabemos que los Parámetros Curriculares Nacionales - PCN recomiendan que las clases de lengua extranjera les proporcionen a los alumnos: la competencia de "saber distinguir entre as variantes linguísticas" (BRASIL, 2000, p. 28) y un nivel de competencia lingüística que les propicie el acceso a informaciones de varios tipos, contribuyendo, así, para su formación como ciudadano. Destacamos, además, que uno de los criterios de adopción de libros didácticos de lengua extranjera exigido por el Programa Nacional del Libro Didáctico (PNLD) es que los mismos tengan "textos representativos das comunidades falantes da língua estrangeira". Notamos que las orientaciones de esos documentos oficiales que reglamentan la enseñanza en Brasil ratifican la importancia de una conexión entre la Sociolingüística y enseñanza de lenguas. De este modo, no hay motivo para que materiales didácticos (MD) de enseñanza de PBE sigan basándose en descripciones nada realistas del portugués. 
Los preceptos adoptados para la producción de MD de PBE deben ser los mismos recomendados para los libros didácticos de lengua materna y de lengua extranjera recomendados por el PNLD, ya que todavía no tenemos una medida específica para la enseñanza de PBE. Además, es importante tomar como referencial los exámenes CELPE-BRAS en la elaboración de materiales didácticos de $\mathrm{PBE}$, a fin de mejor capacitar a los alumnos para la realización de esa evaluación

Según Fragozo (2011, p. 156) "uma das contribuições da Sociolinguística para a Aquisição de LE está relacionada ao que se entende por língua-alvo, muitas vezes confundida com a língua padrão". Para la autora, lengua estándar consiste en la variante de mayor prestigio en la sociedad y lengua objetivo, por otro lado, puede ser cualquier variedad de la lengua aprendida a la que el aprendiz está expuesto y que, por consiguiente, toma como modelo. Es cierto que no siempre el estudiante de lengua extranjera está expuesto a la lengua estándar, sino a otras variantes que influencian directamente su producción de la lengua. Por eso, Fragozo (2011) critica la exagerada valoración de la lengua estándar, en los materiales didácticos de enseñanza de lengua extranjera.

Así, es importante que el profesor de PBE muestre al aluno los diferentes registros de la lengua portuguesa, para que este sea capaz de elegirlos conforme a la situación de comunicación. Gomes de Matos (2007) recomienda que se enseñen a los alumnos los usos formal e informal de la lengua objetivo.

Es evidente que el conocimiento sociolingüístico es importante para la práctica pedagógica, ya que:

Através deste conhecimento, o professor torna-se capaz de considerar as diferenças linguísticas e culturais entre os membros de uma comunidade, assim como seus valores sociais, de modo a desenvolver o currículo e o método mais adequados para determinados contextos de ensino. (FRAGOZO, 2011, p.166)

Retomando al tema de nuestra investigación, en lo que concierne a la enunciación del objeto dentro de un texto o diálogo, en lengua portuguesa de Brasil, hay varias posibilidades para su representación aparte del uso de los clíticos. Por lo tanto, se constituye un fenómeno en variación. Pretendemos, en este artículo, presentar nuestra investigación, en la que examinamos como este aspecto del $\mathrm{PB}$ viene siendo tratado en los materiales didácticos dirigidos a la enseñanza de PBE. 


\section{La realización del complemento verbal en PB}

Todas las lenguas habladas presentan variaciones. Así que eso ocurre tanto en portugués como en español. Sin embargo, en el caso del portugués de Brasil parece que hay una mayor distancia entre la lengua escrita y lengua hablada, variedad(es) estándar y variedad(es) no estándar (DUARTE, 2000). Tal abismo se debe a la manera como se estableció la norma culta en Brasil, en base a un modelo que no era el utilizado acá. Pero lo que nos interesa comentar es como esa diferencia puede interferir en el proceso de enseñanza/aprendizaje de portugués como lengua extranjera. Duarte (2000, p. 1) resalta:

Isso fica patente, por exemplo, quando se vai ensinar português para estrangeiros. Já na primeira lição, o professor encontra problemas com as estruturas com o verbo 'haver', por exemplo. Ele ensina que o que a gramática diz é que "o certo" é: 'há muita gente no jardim', mas diz ao aluno que ele vai ouvir e falar 'tem muita gente no jardim'. Ensina que "o certo" é 'você foi ao cinema?', mas que ele vai ouvir 'você foi no cinema?'. Ensina que escrevemos/deveríamos escrever 'nós não a vimos ontem', mas falamos/ouvimos 'a gente não viu ela ontem'. Ensina que a gramática prescreve 'Contaram-me uma história', mas ele vai ouvir 'Me contaram uma história'.

Vamos a limitarnos al penúltimo ejemplo, pues se refiere a nuestro tema. Según afirman muchos estudiosos (TARALLO, 1990; DUARTE, 2000), el cuadro de clíticos del PB viene sufriendo un proceso de cambio. Muchos están desapareciendo de la lengua oral, como es el caso del pronombre acusativo de $3^{\text {a }}$ persona "a", utilizado en el ejemplo anterior, de tal modo que su uso queda restricto a situaciones más formales tanto en la modalidad oral como en la escrita. Como mostró Duarte (2000) con este ejemplo, en Brasil, es recurrente el reemplazo del clítico acusativo por un pronombre tónico. Otras estrategias de retomada del objeto directo también son frecuentes, como la repetición del sintagma nominal o la omisión del complemento (objeto nulo). Así, hay otras posibles realizaciones para la variable representación del objeto directo anafórico, además de "não vimos ela" son: "não vimos (a) Maria/a menina" o "não ø vimos".

En otro estudio, Duarte (1989) describe, en base a metodología cuantitativa, cuatro procesos de recuperación del OD. El pronombre 
átono aparece como el menos usado para retomar el objeto directo, con un $4,9 \%$ de las ocurrencias; luego, el pronombre ele, con un $15,4 \%$ de las ocurrencias; después, el sintagma nominal anafórico, o sea, la repetición del objeto directo, con un 17,1\% de las ocurrencias; y el proceso más usado, con un $62,6 \%$ de las ocurrencias es la categoría vacía.

Tarallo justifica la preferencia por la omisión del objeto directo:

Uma vez que os pronomes-objeto se encontram em fase de extinção no português falado do Brasil, a luta acaba sendo travada entre as duas formas não-padrão. Das duas a anáfora zero carrega estigma sociolinguístico menos acentuado. (TARALLO, 1990, p. 43)

Por lo tanto, la incidencia mayor del objeto nulo se atribuye al hecho de la sustitución del clítico por un pronombre tónico ser estigmatizada socialmente. Tarallo (1990, p. 43) defiende que la preferencia es aún mayor cuando se trata de un objeto inanimado:

$\mathrm{Na}$ substituição de pronomes clíticos, a língua falada favorece a anáfora zero, acelerando ainda mais o processo de sua implementação no sistema quando o SN pronominalizável (isto é, aquele já usado anteriormente e que deveria retornar como pronome) for inanimado.

En lo que atañe a los pronombres anafóricos de objeto indirecto, también es posible afirmar que los clíticos están desapareciendo de la gramática del portugués brasileño, siendo también omitidos en la modalidad oral del portugués. (TARALLO, 1990, p. 43).

Berlinck (1997) hizo una importante investigación sobre la realización del OI, con corpus de lengua hablada y énfasis en las ocurrencias en que el OI posee valor anafórico. ${ }^{1}$ La autora constató que, en este caso, la categoría vacía es más frecuente (57\%), seguida del pronombre clítico $(26 \%)$ y del sintagma preposicionado con pronombre tónico (17\%). Berlinck (1997) buscó identificar los contextos que favorecen el uso de determinada forma en la posición de objeto indirecto, tales como: la persona gramatical a que se refiere el complemento, el tiempo verbal, distancia entre el complemento anafórico y su referente.

\footnotetext{
${ }^{1}$ El valor anafórico del OI es entendido por Berlinck (1997, p. 1, traducción nuestra) como la "relación de correferencia con un elemento mencionado anteriormente".
} 
En cuanto a la persona a que se refiere el complemento, revela que hay una predominancia de la categoría vacía solo cuando el referente es de $1^{\mathrm{a}}$ o $3^{\mathrm{a}}$ personas gramaticales; el pronombre tónico aparece preferentemente con la $3^{\mathrm{a}}$ persona del discurso; y el pronombre átono predomina con referente de $2^{\mathrm{a}}$ persona.

Al considerar el tiempo del verbo de que el objeto indirecto es complemento, la investigación de Berlink (1997) demostró un equilibrio entre la categoría vacía y el pronombre átono, con verbos en el presente de indicativo. Con verbos en los pretéritos perfecto e imperfecto de indicativo, hubo una mayor ocurrencia de la categoría vacía. El uso de los clíticos predominó con verbos en el futuro del presente de indicativo.

La mencionada investigación también tuvo en cuenta la distancia entre el objeto indirecto anafórico y su referente. En oraciones con referente en la oración inmediatamente anterior, hay una preferencia por el objeto nulo, pero con referentes más distantes ocurre con más frecuencia el objeto lexicalizado.

No podemos dejar de enfatizar el surgimiento de nuevas formas pronominales en el portugués brasileño, utilizadas tanto en la referencia del sujeto, como de los complementos verbales, a saber, você y a gente, en sustitución a tu y nós, respectivamente. Dicho evento promovió la posibilidad de varias combinaciones pronominales, algunas de uso estándar y otras de uso no estándar de la lengua portuguesa brasileña. Lopes (2007, p. 115) atribuye el cambio en el paradigma pronominal a la inserción de las formas innovadoras en el cuadro de pronombres: "É fato que a implementação de você e $a$ gente no sistema de pronomes pessoais gerou uma série de reorganizações gramaticais, tanto no subsistema de possessivos, quanto no de pronomes que exercem função de complementos diretos ou indiretos". Para la autora, el pronombre a gente es más usado que nós, tanto en la función de sujeto como en la de complemento. Además, afirma que tal forma es frecuentemente combinada con el pronombre oblicuo átono de primera persona del plural nos, incluso por hablantes cultos de la lengua. Igualmente, es común la correlación de você con el pronombre átono de segunda persona te, a pesar de que el uso estándar sea con el pronombre de tercera persona.

No hay motivo para dejar de comentar tales hechos con los aprendices hispánicos, incluso porque la lengua española también pasa por fenómenos semejantes, como también observó Lopes (2007, p. 115): "A constituição do paradigma supletivo é resultado de um processo de 
mudança similar ao que ocorreu em outras línguas românicas, como é o caso, por exemplo, do voseo hispano-americano".

Almeida (2011), en un artículo sobre el pronombre lhe, afirma que este pronombre no está en desuso, como lo que ocurre con $o(s), a(s)$, según afirman algunos estudiosos. En verdad, viene siendo menos utilizado en su función prototípica. Ocurre que el uso de esa forma alterna entre la segunda y la tercera persona y entre el dativo y el acusativo. Al empleo del pronombre lhe en función de objeto directo se da el nombre de lheísmo. Este fenómeno se puede justificar como una analogía al funcionamiento de las formas pronominales que no son de tercera persona.

Al citar la investigación de Ramos (1999), Almeida (2011) comenta los tres comportamientos en el uso del pronombre lhe descriptos por aquella:

1) Rio-São Paulo: the usado para expresión del dativo de segunda persona del discurso, relación de respeto/cortesía y te para la relación familiar, aunque você sea usado tanto en las relaciones de respeto, como de familiaridad.

2) Maceió, Recife, Salvador y João Pessoa: lhe reemplaza te como dativo y como acusativo, su uso no está limitado a situaciones formales.

3) Región Norte y Maranhão: Você/lhe son usados en el tratamiento de cortesía y tu/te, en el tratamiento familiar. Los clíticos lhe y te son usados tanto para el dativo como para el acusativo.

En la Gramática Brasileña para hablantes de español, Carvalho y Bagno (2015) presentan un cuadro muy completo de los pronombres personales de la lengua portuguesa hablada en Brasil, incluyendo você y a gente, así como la forma $o$ senhor para el tratamiento formal. Los autores también comentan las correlaciones pronominales posibles, en la variedad brasileña del portugués.

En lo que concierne a la representación del complemento verbal, que es el eje de este trabajo, Carvalho y Bagno (2015, p. 46) afirman que los pronombres de objeto directo, de tercera persona $o(s), a(s)$ "ya no pertenecen a la lengua espontánea brasileña y los usan únicamente las personas con acceso a la educación formal. Su empleo se restringe a los textos escritos formales". 
Carvalho y Bagno (2015, p. 46) registraron que, para reemplazar el objeto directo de tercera persona, los brasileños prefieren usar los pronombres tónicos ele $(s)$ y ela(s) o no utilizar ningún pronombre. Es importante mencionar que los autores constataron que el primer caso es bastante frecuente con verbos en imperativo. Algunos de los ejemplos dados son los siguientes:

(a) Eu comprei um terreno aqui no interior por três mil, mas já vendi ele para um parente.

(b) Eu comprei um terreno aqui no interior por três mil, mas já vendi $\varnothing$ para um parente.

(c) Para de incomodar a Aninha. Deixa ela em paz! (imperativo)

En relación a la segunda persona singular, Carvalho y Bagno (2015, p. 47) señalan las diversas posibilidades de formas oblicuas utilizadas en la correlación con você:

CUADRO 1 - Formas oblicuas utilizadas en la correlación con você

\begin{tabular}{|l|l|}
\hline \multicolumn{1}{|c|}{ Objeto directo } & \multicolumn{1}{c|}{ Objeto indirecto } \\
\hline Se você quiser ir comigo, eu te levo. & $\begin{array}{l}\text { Sabe o dinheiro que você me emprestou? Amanhã } \\
\text { vou te devolver. }\end{array}$ \\
\hline Se você quiser ir comigo, eu lhe levo. & $\begin{array}{l}\text { Sabe o dinheiro que você me emprestou? Amanhã } \\
\text { vou lhe devolver. }\end{array}$ \\
\hline $\begin{array}{l}\text { Se você quiser ir comigo, eu levo } \\
\text { você. }\end{array}$ & $\begin{array}{l}\text { Sabe o dinheiro que você me emprestou? Amanhã } \\
\text { vou devolver pra você. }\end{array}$ \\
\hline
\end{tabular}

Fuente: Carvalho y Bagno (2015)

Otra observación importante es la que se refiere al empleo de $o(s), a(s)$ en sustitución a você. Carvalho y Bagno (2015, p. 48) dicen que ese uso es bastante formal y ocurre solamente con verbos en infinitivo.

En cuanto al objeto indirecto de tercera persona, según Carvalho y Bagno (2015, p. 48), el pronombre átono the solo es utilizado en textos escritos formales. En su lugar, lo que se suele utilizar es también

${ }^{2}$ Los autores hacen el siguiente comentario acerca de ese ejemplo: "El empleo de the como objeto directo se restringe al habla informal de algunas variedades regionales" (CARVALHO; BAGNO, 2015, p. 47) 
el pronombre tónico ele/ela, juntamente con una preposición para o $a$ (para ele/a, ele).

En verdad, sabemos que no se trata solo de una cuestión de situación formal/ informal o de modalidad escrita/oral. Las fronteras que delimitan las variedades son más tenues y se entrecruzan. Por ello, algunos autores (BORTONI-RICARDO, 2004; NEVES, 2003) prefieren hablar de continuos. Son los papeles sociales ${ }^{3}$ que desempeñamos que van a dictar la variante que utilizaremos. Por lo tanto, un mismo hablante puede usar el pronombre ele en función de objeto directo o indirecto y, en otra situación, dirigiéndose a otro interlocutor, utilizar la variante prescrita por la norma culta, o sea, los pronombres oblicuos o/a o lhe. Es evidente que este tipo de elección solo la puede hacer un hablante culto, que tuvo acceso a educación y tiene conciencia de la necesidad de variar su discurso, a fin de hacerse comprender

\section{Análisis del Corpus}

Analizamos cualitativamente el contenido de los materiales didácticos antes mencionados, a fin de averiguar si se consideraron los presupuestos de la sociolingüística en su producción. Podemos describir los procedimientos adoptados de la siguiente manera:

- Descripción del tratamiento dado a la cuestión de la representación del complemento verbal (CV), en cada material, con el fin de averiguar si la variación lingüística está contemplada en alguna de sus partes, ya sea en los ejercicios propuestos, en los textos, en los enunciados, o en la parte teórica.

- Examen de la estrategia presentada para representación del CV a fin de verificar si corresponde solo al paradigma tradicional o toma en cuenta las otras variedades.

- En el caso de que el material didáctico contemple la variación lingüística, verificar si ese abordaje ocurre de manera superficial, como una especie de comentario sobre una curiosidad de la lengua o como hecho lingüístico.

- Discusión del paradigma pronominal presentado en los libros didácticos.

\footnotetext{
${ }^{3}$ Sobre papeles sociales ver Bortoni-Ricardo (2004, p. 23) y Preti (2004, p. 14).
} 
El análisis de libros didácticos que realizamos evidenció la pobreza de esos materiales en lo que conciene al tratamiento de la variación lingüística. Ya es posible notar algún cambio en la producción de esos materiales en comparación a ediciones anteriores a las seleccionadas para esta investigación, en el sentido de introducir palabras y construcciones que antes eran totalmente despreciadas, por ser desprestigiadas. Se nota actualmente una preocupación en enseñar la lengua hablada, pues de los libros analizados la mayoría posee una declaración sobre eso. Buscamos esa información en la contraportada, en la Presentación o en la solapa de cada material analizado. Solo en dos libros no hemos encontrado la afirmación de que el método se propone a enseñar la lengua hablada: Panorama Brasil y Siempre Amigos. El primero se propone a enseñar el portugués del mundo de los negocios y, por ello, tiene enfoque en la enseñanza de la variedad culta del PB. El segundo libro no posee ninguna afirmación de que se propone a enseñar el portugués hablado, aunque su público objetivo sea adolescente y posea un lenguaje bastante informal.

La tabla a continuación demuestra la contribución de los estudios lingüísticos en la producción de materiales didácticos de enseñanza de PBE. En muchos libros hay registros de variantes no estándar, no solo en lo que toca a la variable representación del CV en PB, sino especialmente en lo concerniente al léxico. Contradictoriamente, pocos presentan propuestas de ejercicios para la práctica de variantes no estándar.

TABLA 1 - Contribuciones de los estudios lingüísticos en la producción de MD de PBE

\begin{tabular}{|c|c|c|c|}
\hline Libro & $\begin{array}{c}\text { Propone enseñar la } \\
\text { lengua hablada }\end{array}$ & $\begin{array}{c}\text { Registro de variantes } \\
\text { no estándar }\end{array}$ & $\begin{array}{c}\text { Ejercicios para la } \\
\text { práctica del uso de } \\
\text { variantes no estándar }\end{array}$ \\
\hline APB & $\mathrm{x}$ & $\mathrm{x}$ & \\
\hline BV & $\mathrm{x}$ & & \\
\hline EB & $\mathrm{x}$ & $\mathrm{x}$ & $\mathrm{x}$ \\
\hline MP & $\mathrm{x}$ & & \\
\hline NAB & $\mathrm{X}$ & & $\mathrm{x}$ \\
\hline PB & & $\mathrm{x}$ & \\
\hline PAS & $\mathrm{x}$ & $\mathrm{x}$ & \\
\hline PVB & $\mathrm{x}$ & $\mathrm{x}$ & \\
\hline SA & & $\mathrm{x}$ & \\
\hline TB & & & \\
\hline
\end{tabular}


MP presenta actividades que contemplan variantes no estándar solamente sobre OI. Los ejercicios de OD son normativos. Las actividades propuestas en PAS son para la práctica de reemplazo de lhe por te, en la correlación con você y de la colocación pronominal no estándar.

Otro punto en que podemos notar la contribución de los estudios lingüísticos en la producción de LD de PBE es la enseñanza de los usos de los pronombres personales. Se nota, por ejemplo, la introducción de la forma você al cuadro pronominal y, en algunos casos, también de la forma a gente. En lo concerniente al primer pronombre incluso notamos una preferencia por la enseñanza de esa forma y el desprecio del pronombre $t u$, lo que también consideramos una equivocación, ya que ambos los pronombres se utilizan todavía en PB. Sobre la enseñanza de los pronombres personales sujeto presentamos la siguiente tabla:

TABLA 2 - Cuadro pronominal presentado - Pronombre sujeto

\begin{tabular}{|c|c|c|c|c|c|}
\hline Libro & $\begin{array}{c}\text { Incluye el } \\
\text { pronombre } \\
\text { você }\end{array}$ & $\begin{array}{c}\text { Incluye el } \\
\text { pronombre } \\
t u\end{array}$ & $\begin{array}{c}\text { Incluye la } \\
\text { forma } a \\
\text { gente }\end{array}$ & $\begin{array}{c}\text { Incluye } o \\
\text { senhor, } a \\
\text { senhora }\end{array}$ & $\begin{array}{c}\text { Incluye el } \\
\text { pronombre } \\
\text { vós }\end{array}$ \\
\hline APB & $\mathrm{x}$ & $\mathrm{x}$ & & $\mathrm{x}$ & \\
\hline BV & $\mathrm{x}$ & $\mathrm{x}$ & & & $\mathrm{x}$ \\
\hline MP & $\mathrm{x}$ & & $\mathrm{x}$ & & \\
\hline NAB & $\mathrm{x}$ & $\mathrm{x}$ & & $\mathrm{x}$ & \\
\hline PB & $\mathrm{x}$ & $\mathrm{x}$ & & & \\
\hline PAS & $\mathrm{x}$ & & $\mathrm{x}$ & $\mathrm{x}$ & \\
\hline SA & $\mathrm{x}$ & $\mathrm{x}$ & $\mathrm{x}$ & $\mathrm{x}$ & \\
\hline TB & $\mathrm{x}$ & $\mathrm{x}$ & & & $\mathrm{x}$ \\
\hline
\end{tabular}

No se menciona EB en la tabla anterior, pues no presenta ningún tipo de contenido gramatical, incluyendo los pronombres. En PVB, que tampoco consta de la tabla, no hay sistematización de los pronombres personales nominativos. Con relación a la enseñanza de los pronombres de segunda persona singular, en el libro NAB, el pronombre $t u$ aparece en un comentario que dice que "é usado em Portugal e em algumas regiões do Brasil". Por otro lado, en TB, se comenta solo que el pronombre tu 
es bastante usado en el sur de Brasil. En lo que atañe a la inclusión de la forma innovadora a gente, los libros PAS y SA poseen una advertencia sobre el hecho de tratarse de una expresión equivalente a nós. Sobre la enseñanza del tratamiento formal de segunda persona del discurso, en NAB y SA, o senhor/a senhora aparecen en un comentario y, en el libro PAS, esos pronombres están incluidos en el cuadro de pronombres de tratamiento y no en el de pronombres personales. Finalmente, en lo que concierne a la enseñanza del pronombre de segunda persona plural vós, solo en TB se aclara que este pronombre es encontrado en textos antiguos.

Queda evidente que todavía falta darle al uso de los pronombres personales en PB la importancia que se le debe. No basta aparecer solo como comentarios y observaciones, como si fueran solo una curiosidad de la lengua. Es fundamental, por ejemplo, explicar las posibilidades combinatorias de los pronombres complemento con la forma você, como se demuestra en la siguiente tabla:

TABLA 3 - Cuadro pronominal presentado - Pronombre complemento

\begin{tabular}{|c|c|c|c|c|}
\hline Libro & $\begin{array}{c}\text { Incluye el } \\
\text { pronombre você }\end{array}$ & $\begin{array}{c}\text { Incluye la } \\
\text { forma a gente }\end{array}$ & $\begin{array}{c}\text { Incluye } o \\
\text { senhor, a } \\
\text { senhora }\end{array}$ & $\begin{array}{c}\text { Correlación te } \\
+ \text { você }=\text { lengua } \\
\text { hablada }\end{array}$ \\
\hline APB & & & $\mathrm{x}$ & $\mathrm{x}$ \\
\hline \multicolumn{5}{|l|}{ BV } \\
\hline \multicolumn{5}{|l|}{ EB } \\
\hline MP & $\mathrm{x}$ & $\mathrm{x}$ & & $\mathrm{x}$ \\
\hline \multicolumn{5}{|l|}{ NAB } \\
\hline \multicolumn{5}{|l|}{ PB } \\
\hline PAS & & & & $\mathrm{x}$ \\
\hline \multicolumn{5}{|l|}{ PVB } \\
\hline \multicolumn{5}{|l|}{ SA } \\
\hline TB & $\mathrm{x}$ & & & \\
\hline
\end{tabular}

Vemos entonces que solo tres libros enseñan la posibilidad combinatoria de te y você, en el portugués hablado. En el libro PAS, esa información aparece en un cuadro donde se lee: "lhe = para você, 
informal = te". También llama la atención el hecho de que, aunque la mayoría de los libros analizados incluya el pronombre você en la lista de pronombres personales sujeto, solamente dos lo incluyen en el cuadro de pronombres complemento. Siendo que MP lo integra solamente como OI y, en TB, el pronombre no aparece en el cuadro pronominal, sino como un ejemplo en una advertencia: "convidar vocês ou convidá-los".

Por último, con relación al tratamiento dado a la cuestión de la representación del objeto, proponemos la tabla a continuación para ilustrar nuestro análisis.

TABLA 4 - Tratamiento dado a la cuestión de la representación del objeto

\begin{tabular}{|c|c|c|c|}
\hline Libro & $\begin{array}{l}\text { Solo representación } \\
\text { por los clíticos }\end{array}$ & $\begin{array}{c}\text { Representación por } \\
\text { pronombre tónico }\end{array}$ & $\begin{array}{c}\text { Alusión a la } \\
\text { categoría vacía }\end{array}$ \\
\hline APB & $\mathrm{x}$ & & \\
\hline BV & $\mathrm{x}$ & & $\mathrm{x}$ \\
\hline \multicolumn{4}{|l|}{ EB } \\
\hline MP & $\mathrm{x}$ & & \\
\hline NAB & $\mathrm{x}$ & & \\
\hline PB & $\mathrm{x}$ & & \\
\hline PAS & $\mathrm{x}$ & & \\
\hline PVB & $\mathrm{x}$ & & \\
\hline SA & & $\mathrm{x}$ & \\
\hline TB & & $\mathrm{x}$ & \\
\hline
\end{tabular}

Como se ve, la mayoría de los materiales analizados todavía posee un tratamiento normativo de la representación del complemento verbal, puesto que hay un predominio de la enseñanza de la representación por el clítico, que es la prescripción de la tradición gramatical. Sin embargo, se notan algunos comentarios importantes, como en BV, en que hay una observación sobre algunas frases que contienen clíticos: "Observe que o uso desses pronomes deixa o diálogo com um tom bastante formal" y, en el libro MP, en el que se exponen ejemplos y a continuación aparece la siguiente observación: "Não é usado na linguagem oral". Por otro lado, 
solamente un libro menciona la posibilidad de objeto nulo, que es el modo más frecuente de representación del complemento verbal, en PB. En tal libro se alude a la categoría vacía por medio del siguiente comentario: "O pronome oblíquo 4 é facultativo". Ya en cuanto a la representación del OD por pronombre tónico, dos materiales registran esa variante, SA y TB. En esos libros, hay diálogos en que aparece el pronombre ele en la función de OD, seguidos de una advertencia sobre tratarse de lenguaje coloquial. En el libro TB, sin embargo, encontramos la frase "No use" antes de los ejemplos, sin especificar los contextos en que el uso no es apropiado.

Queda evidente, entonces, que lo que predomina todavía es una visión normativa y no sociolingüística de la lengua, con enfoque en lo que es "equivocado", no considerando factores pragmáticos como la adecuación del enunciado a la situación comunicativa. En otras palabras, en la mayoría de los manuales analizados, cuando alguna variedad no estándar aparece, es con la intención de señalar lo que no se debe decir o escribir (estamos refiriéndonos al tema de este estudio).

Como vimos, el tema de los pronombres átonos y demás estrategias de representación del complemento verbal todavía no es contemplado en toda su complejidad, en los materiales didácticos de portugués para extranjeros. Aún es necesario detallar mejor las diferencias del continuo "habla y escritura", que existen en el portugués brasileño. Asimismo enfatizamos la necesidad de la elaboración de un material didáctico específico para hispanohablantes, que parta del análisis contrastivo entre las dos lenguas.

Sin embargo, debemos aclarar que no pretendemos desvalorar el conocimiento de la norma culta, en el proceso de aprendizaje de una lengua. Creemos sí en la enseñanza de la gramática, pero de forma contextualizada, pues es necesario considerar que nuestro discurso debe adecuarse al contexto de producción textual. Ello implica una práctica docente que se base en los diversos géneros textuales. Por lo tanto, el resultado que se espera es que el alumno que aprende una lengua extranjera sepa comunicarse adecuadamente, en las diversas situaciones comunicativas.

4 “Pronome oblíquo" es la denominación en portugués para el pronombre complemento. 


\section{Consideraciones finales}

Retomamos nuestra afirmación inicial de que, debido a la semejanza entre portugués y español, el alumno que aprende una de las dos lenguas como lengua extranjera (LE), presenta muchas dificultades para salir de la fase de interlengua, conocida popularmente como "portuñol". De este modo, queremos proponer una enseñanza que tome como punto de partida el análisis contrastivo para la identificación de los elementos que pueden causar problemas en el desempeño lingüístico del hispanohablante aprendiz de portugués.

Uno de esos elementos es la diferencia que existe entre el PB y el español en la representación del complemento verbal. Lo demostramos con la síntesis que hicimos, con base a gramáticas de ambas las lenguas. El resumen de algunos estudios sociolingüísticos sobre la representación del CV también evidenció dicha diferencia. Con todo, los materiales didácticos analizados en esta investigación no examinan ese punto de la gramática portuguesa, o sea, no describen toda la riqueza de las estrategias de retomada del $\mathrm{CV}$ posibles en $\mathrm{PB}$. Algunos materiales solo mencionan el hecho de ser común el uso del pronombre tónico en la representación del objeto y también la omisión del CV, pero sin la necesaria profundización, solo como una observación. Eso es inadmisible si consideramos que el objeto nulo es la estrategia más utilizada para representar el CV. Por lo tanto, la variación en ese hecho lingüístico, indubitablemente, merece una explicación más detallada y contextualizada.

La mayoría de los libros objeto de esta investigación posee un carácter meramente normativo, de enseñanza tradicional, con énfasis en factores estructurales, lo que contraría muchas veces las declaraciones encontradas en la parte introductoria o en la contraportada de los mismos materiales, que los describen como modernos y de metodología comunicativa. Muchas contraportadas exhiben la información de que el material preparará al alumno para comunicarse en diversas situaciones comunicativas, pero su contenido no describe todas las variedades.

Al partir de la idea de que enseñar una lengua extranjera significa ampliar los horizontes del alumno, podemos afirmar que enseñarle solo la variedad estándar del idioma es hacer exactamente lo contrario, es limitarlo. Es necesario presentarle al discente el abanico de posibilidades y orientarlo a adecuarlas a las diversas situaciones de comunicación. 
Aún considerando la enseñanza de $\mathrm{PBE}$ en la perspectiva comunicativa de desarrollo de habilidades, se espera, delante de la escasez de materiales didácticos específicos para hablantes de español publicados en Brasil, que este estudio pueda colaborar para la planificación de estrategias de enseñanza, sirviendo como material de apoyo a profesores, o como base para la elaboración de materiales didácticos en general.

\section{Referencias}

ALMEIDA, Gilce de Souza. Prescrição gramatical e uso: o caso do pronome lhe no português brasileiro. Cadernos do CNLF, Rio de Janeiro: CiFEFiL, v. XV, n. 5, t. 3, p. 2398-2408, 2011. Disponible en: <http:// www.filologia.org.br/xv_cnlf/tomo_3/204.pdf $>$. Acceso el: 6 maio 2016.

BERLINK, Rosane de Andrade. Sobre a realização do objeto indireto no português do Brasil. In: ENCONTRO DO CELSUL (CIRCULO DE ESTUDOS LINGUÍSTICOS DO SUL), II., 1997, Florianópolis. Anais... Florianópolis: UFSC, 1997.

BIZON, Ana Cecília; FONTÃO, Elizabeth. Estação Brasil: português para estrangeiros. Campinas: Átomo, 2005.

BORTONI-RICARDO, S. M. Problemas de comunicação interdialetal. Revista Tempo Brasileiro, Rio de Janeiro, n. 78/79, p. 9-32, 1984.

BORTONI-RICARDO, S. M. Educação bidialetal - O que é? É possível? In: SEKI, Lucy (Org.). Linguística indígena e educação na América Latina. Campinas: UNICAMP, 1993. p. 71-88.

BORTONI-RICARDO, S. M. A variação linguística em sala de aula. In: . Educação em língua materna: a sociolinguística na sala de aula.

São Paulo: Parábola, 2004. p. 37-44

BRASIL. Ministério da Educação. Parâmetros Curriculares Nacionais: Enseñanza Médio - Linguagens Códigos e suas Tecnologias. Brasília: MEC/SEF, 2000.

CARVALHO, Orlene Lúcia S.; BAGNO, Marcos. Gramática brasileña para hablantes de español. São Paulo: Parábola, 2015.

CELLI, Rosine. Passagens: Português do Brasil para estrangeiros. Campinas: Pontes, 2002. 
CYRINO, Sonia Maria Lazzarini. O objeto nulo no português do Brasil: um estudo sintático-diacrônico. Londrina: Editora da UEL, 1997.

DUARTE, Maria Eugênia Lamoglia. Clítico acusativo, pronome lexical e categoria vazia no português brasileiro. In: TARALLO, F. (Org.). Fotografias sociolinguísticas. Campinas: Pontes; Editora da Unicamp, 1989. p.19-34.

DUARTE, Maria Eugênia Lamoglia. Enseñanza da língua em contexto de mudança. 2000. Disponible en: <http://www.filologia.org.br/anais/ anais\%20iv/civ12_3.htm>. Acceso el: 8 mar. 2016.

FERNANDES, Gláucia Roberta Rocha; FERREIRA, Telma de Lurdes; RAMOS, Vera Lúcia. Muito prazer: fale o português do Brasil. São Paulo: Disal, 2014. v. 2.

FLORISSI, Susanna; PONCE, Maria Harumi Otuki de; BURIM, Silvia R. B. Andrade. Bem-vindo! A língua portuguesa no mundo da comunicação. 8. ed. São Paulo: Special Book Services Livraria, 2014.

FLORISSI, Susanna; PONCE, Maria Harumi Otuki de; BURIM, Silvia R. B. Andrade. Panorama Brasil: enseñanza de português no mundo dos negócios. São Paulo: Galpão, 2006.

FLORISSI, Susanna; PONCE, Maria Harumi Otuki de; BURIM, Silvia R. B. Andrade. Tudo bem? Português para a nova geração. 5. ed. São Paulo: Special Book Services Livraria, 2012. v. 1.

FONTÃO, Elizabeth; COUDRY, Pierre. Sempre amigos: fala Brasil para jovens. Campinas, SP: Pontes, 2000.

FRAGOZO, Carina Silva. Cultura e sociolinguística no enseñanza e na aprendizagem de língua estrangeira. Fólio Revista de Letras, Vitória da Conquista, v. 3 n. 1, p. 151-67, jan./jun. 2011. Disponible en: $<$ http:// periodicos.uesb.br/index.php/folio/article/view/529>. Acceso el: 28 jun. 2016.

GOMES DE MATOS, Francisco. Influência da Linguística em materiais didáticos para Enseñanza de Português como língua estrangeira: uma perspectiva brasileira. Linguística - Revista de Estudos Linguisticos da Universidade do Porto, Porto, Portugal, v. 2, p. 47-59, 2007. Disponible en: $<$ http://ler.letras.up.pt/uploads/ficheiros/6864.pdf $>$. Acceso el: 29 jun. 2016. 
LABOV, William. Sociolinguistic Patterns. Philadelphia: University of Pennsylvania Press, 1972.

LAROCA, Maria N. de Carvalho. Aprendendo Português do Brasil: um curso para estrangeiros. 4. ed. Campinas: Pontes, 2003.

LIMA, Emma Eberlein O. F. et al. Novo Avenida Brasil: curso básico de Português para estrangeiros 1. São Paulo: Editora Pedagógica e Universitária, 2009.

LIMA, Emma Eberlein O. F.; IUNES, Samira A. Português Via Brasil: um curso avançado para estrangeiros. São Paulo: Editora Pedagógica e Universitária, 2005.

LOPES, Célia Regina. Pronomes pessoais. In: VIEIRA, Sílvia Rodrigues; BRANDÃO, Sílvia Figueiredo (Org.). Ensino de gramática: descrição e uso. São Paulo: Contexto, 2007. p. 103-119.

MAIA GONZÁLEZ, Neide. Sobre a aquisição de clíticos do espanhol por falantes nativos do português. Cad. Est. Ling., Campinas, n. 36, p. 163-176, jan./jun. 1999. Disponible en: <http://revistas.iel.unicamp. br/index.php/cel/article/view/1661>. Acceso el: 6 maio 2016.

MAIA GONZÁLEZ, Neide. Portugués brasileño y español: lenguas inversamente asimétricas. SIGNOS ELE, Buenos Aires, n. 1-2, dic. 2008. [CELADA, María Teresa; Neide MAIA GONZÁLEZ (Coord. dossier). Gestos trazan distinciones entre la lengua española y el portugués brasileño.] Disponible en: <http://p3.usal.edu.ar/index.php/ele/article/ view/1394>. Acceso el: 12 abr. 2018.

NEVES, Maria Helena de Moura. Que gramática estudar na escola? Norma e uso na Língua Portuguesa. São Paulo: Contexto, 2003.

PRETI, Dino. Estudos de língua oral e escrita. Rio de Janeiro: Lucerna, 2004.

RAMOS, Conceição de Maria Araújo. O clítico de $3^{a}$ pessoa: um estudo comparativo português brasileiro/espanhol peninsular. 1999. Tese (Doutorado em Linguística) - Universidade Federal de Alagoas, Maceió, 1999.

RODRIGUES, Thaís Leal. Uso dos pronomes átonos em português por hispanofalantes. 2012. $20 \mathrm{f}$. Trabalho de Conclusão de Curso (Especialização) - Instituto de Letras, Universidade Federal Fluminense, Niterói, 2012. 
SANTOS, Percília. O enseñanza de português como segunda língua para falantes de espanhol: teoria e prática. In: SANTOS, Percília; CUNHA, M. J. Enseñanza e pesquisa em Português para estrangeiros. Brasília: EDUNB, 1999.

TARALLO, Fernando. Relativization Strategies in Brazilian Portuguese. 1983. Tese (Doutorado) - University of Pennsylvania, EUA, 1983.

TARALLO, Fernando. A pesquisa sociolinguística. 3. ed. São Paulo: Ática, 1990. 